\title{
Back disorders and lumbar load in nursing staff in geriatric care: a comparison of home-based care and nursing homes Kathrin Kromark*1, Madeleine Dulon ${ }^{1}$, Barbara-Beate Beck ${ }^{2}$ and Albert Nienhaus ${ }^{1}$
}

\author{
Address: ${ }^{1}$ Institution for Statutory Accident Insurance and Prevention in the Health and Welfare Services, Pappellallee 35/37, 22089 Hamburg, \\ Germany and ${ }^{2}$ Forum fBB, Moränenweg 7, 22143 Hamburg, Germany \\ Email: Kathrin Kromark* - kathrin.kromark@bgw-online.de; Madeleine Dulon - madeleine.dulon@bgw-online.de; Barbara- \\ Beate Beck - barbara-beate.beck@forumfbb.de; Albert Nienhaus - albert.nienhaus@bgw-online.de \\ * Corresponding author
}

Published: 10 December 2009

Journal of Occupational Medicine and Toxicology 2009, 4:33 doi:10.1 186/1745-6673-4-33

This article is available from: http://www.occup-med.com/content/4/I/33

(c) 2009 Kromark et al; licensee BioMed Central Ltd.

This is an Open Access article distributed under the terms of the Creative Commons Attribution License (http://creativecommons.org/licenses/by/2.0), which permits unrestricted use, distribution, and reproduction in any medium, provided the original work is properly cited.
Received: 7 July 2009

Accepted: 10 December 2009

\begin{abstract}
Background: Back pain is one of the most frequent complaints in the nursing profession. Thus, the 12-month prevalence of pain in the lumbar spine in nursing staff is as high as $76 \%$. Only a few representative studies have assessed the prevalence rates of back pain and its risk factors among nursing staff in nursing homes in comparison to staff in home-based care facilities. The present study accordingly investigates the prevalence in the lumbar and cervical spine and determines the physical workload to lifting and caring in geriatric care.
\end{abstract}

Methods: 1390 health care workers in nursing homes and home care participated in this cross sectional survey. The nursing staff members were examined by occupational physicians according to the principals of the multistep diagnosis of musculoskeletal disorders. Occupational exposure to daily care activities with patient transfers was measured by a standardised questionnaire. The lumbar load was calculated with the Mainz-Dortmund dose model. Information on ergonomic conditions were recorded from the management of the nursing homes. Comparisons of all outcome variables were made between both care settings.

Results: Complete documentation, including the findings from the occupational physicians and the questionnaire, was available for $41 \%$. Staff in nursing homes had more often positive orthopaedic findings than staff in home care. At the same time the values calculated for lumbar load were found to be significant higher in staff in nursing homes than in home-based care: $45 \%$ vs. $6 \%$ were above the reference value. Nursing homes were well equipped with technical lifting aids, though their provision with assistive advices is unsatisfactory. Situation in home care seems worse, especially as the staff often has to get by without assistance.

Conclusions: Future interventions should focus on counteracting work-related lumbar load among staff in nursing homes. Equipment and training in handling of assistive devices should be improved especially for staff working in home care. 


\section{Background}

Back pain is one of the most frequent complaints in the population in industrialized countries - for example the 12 -month prevalence of chronic back pain in Germany in 2003 was $16 \%$ in men and $22 \%$ in women (three months and longer-lasting; almost daily). $57 \%$ of men and $66 \%$ of women reported that they had suffered from back pain (of any duration or intensity) within the previous 12 months [1]. Back pain is also a very prevalent condition among health care workers. Thus, for health care workers in different specialities, the 12 -month prevalence for pain in the lumbar spine has been reported as being as high as $76 \%$ and in the cervical spine as high as $60 \%$ [2-5]. The resulting disability has enormous consequences for working life both in terms of human suffering, as well as in direct and indirect economic costs from lost working days and reduced productivity [6].

There is a growing number of older people in need of health care and services [7] and it is expected that this will lead to a considerable rise in the demand for professional nursing personnel - exceedingly in nursing homes. That demand can presumably not be met in the coming decades by training adequate numbers of new staff [8]. For this reason, it is desirable that health care workers should be professionally active for long periods of their working life. One effective way to help to achieve this goal would be to encourage preventive measures to avoid diseases related to intervertebral discs, as geriatric care is regarded as being particularly stressful for the back - especially for older health care workers [9-12]. Moreover, routine data from the Institution for Statutory Accident Insurance and Prevention in the Health and Welfare (BGW) have shown that $23.5 \%$ of the reported cases of occupational diseases of the lumbar spine related to the lifting or carrying of heavy loads were working in geriatric care, showing that this is the most affected sector within the health service [13].

In 2007, a total of 572,211 health care workers were active in geriatric care, of which $31 \%$ worked in home care facilities $[14,15]$. In spite of its size, the group of home care nursing staff has only been examined in a few representative studies [3,16-18]. The present study accordingly records orthopaedic findings on back disorders, intensity of back complaints, physical work load and work ability in nursing staff in nursing homes and home-based care.

\section{Methods}

The study was advertised in specialized journals, to enrol occupational physicians in the study. The interested physicians then encouraged the facilities to take part in the study. A total of 137 geriatric care facilities throughout Germany were contacted. $63 \%$ of these facilities took part in the study (68 nursing homes and 18 home care serv- ices). A total of 3390 health care workers were contacted in the participating facilities. Documents were returned by 2164 persons (64\%). Complete documentation - including the findings from the occupational physicians and a questionnaire completed by the respondents - was available for 1390 persons (41\%). Participation in the study was voluntary; all subjects gave informed written consent. The study was approved by the Hamburg Medical Council.

Nursing staff was divided into three job categories: registered nurses (for general care or geriatric care) with an officially recognised diploma after a three-year training, nursing aides (including assistant nurses) with at least a one-year nursing training without examination, and nursing auxiliaries with less or no formal nursing training.

41 occupational physicians performed the orthopaedic examination. They were given training by an orthopaedic specialist in the orthopaedic examination techniques, in order to standardise data collection. Data on the intensity of the back pain in the previous four weeks and on inability to work during the preceding 12 months were recorded by the physicians. The orthopaedic examination was based on the principles of the multistep diagnosis of musculoskeletal disorders (MSD) [19]. This is a graduated examination scheme for the diagnosis of musculoskeletal disease, conceived and validated for use in occupational medical examinations $[20,21]$. For the present study, the original MSD examination procedure was slightly modified and consisted of a basic examination ( 25 items) and a complementary examination (15 items) and covered the regions of the cervical and lumbar spines. The basic examination identified abnormal features of the musculoskeletal system by inspecting the volunteers when walking or standing, by testing the mobility of the joints (actively by the patient and passively by the investigator) and by palpation. The complementary examination was performed if one of five key tests (back pain, painful inclination in the area of the lumbar spine, painful percussion in the area of the lumbar spine, the Kemp sign, or sick leave in the preceding 12 months) was documented as being positive. The complementary examination included 8 tests. In the context of the study, an orthopaedic finding was rated as abnormal if one of the criteria for the cervical or lumbar spines was documented as being positive ("yes"), or lay outside the normal range.

[See additional file 1]

The study subjects had to complete a standardised questionnaire, giving information about sociodemographic and profession-related data (training, employment status, duration of nursing experience), and the frequency of load related activities combined with patient transfers. Other components of the questionnaire were: 
- Work ability (WA): WA was estimated by the subjects using the Work Ability Index (WAI). For the present study, two dimensions of the WAI were selected, dimension 2 "WA with respect to the physical and psychological demands of the work" and dimension 7 "mental resources"). The values for the WAI dimensions were calculated according to standardised coding instructions $[22,23]$.

- Pain intensity: Information was recorded on the intensity of the pain in the regions of the cervical and lumbar spines for the 4 weeks preceding the questionnaire. Pain intensity was described according to the Graded Chronic Pain Status (GCPS) on a 10-point scale [24]. For the analysis, the scale was classified into three degrees of severity: no pain to light pain (0-3); moderate pain (4-6); intense to highly intense pain (7-10) [25].

- History of back diseases: Earlier back diseases were registered by recording the utilisation of medical services because of back pain in the preceding 12 months. This included treatment in a rehabilitation program or an individual consultation with the occupational physician.

Information on working conditions - such as the number of height adjustable patient beds, technical aids (like bath lifts and mobile lifter systems) and low tech ergonomic aids such as sliding sheets, transfer belts and anti-slip mats - were recorded from a telephone interview with the facility management.

Body mass index (BMI) was calculated on the basis of selfreported data as the ratio of body weight $(\mathrm{kg})$ to the square of the height $(\mathrm{m})$, adjusted by a correction factor. The values for BMI were divided into three groups, $<25$ (normal range), 25 to $<30$ (overweight), and $\geq 30$ (obese).

The Mainz-Dortmund dose model (MDD) was used for the assessment of the lumbar load for care actvities with patient transfers [26,27]. This instrument was developed to calculate cumulative forces to the lumbar spine over the entire working life in occupational groups heavily exposed to carrying or lifting. For health care workers, 12 single activities were classified as "load related activities". Reference values of the lumbar load for these activities lie between $2.9 \mathrm{kN}$ and $7.3 \mathrm{kN}$, as recommended by Theilmeier [28]. The frequencies of these load related activities were calculated semiquantitatively on the basis of the individual frequency data in the questionnaire (0-4, 5-10 or more than 10 times per shift). Specific values were assigned to each category to be used in the calculation, namely $2.5,7.5$ and 12.5 , respectively. The lumbar disc compression force was calculated for health care workers in full time employment from the following formula [26]:

$$
D_{r}=\sqrt{\frac{\sum_{\mathrm{i}}\left(\mathrm{F}_{\mathrm{i}}^{2} \times \mathrm{t}_{\mathrm{i}}\right)}{8 \mathrm{~h}}} \times 8 \mathrm{~h}
$$

$\mathrm{D}_{\mathrm{r}}$ : Lumbar disc compression force, MDD daily dose (Newton times hours, Nh)

$\mathrm{F}_{\mathrm{i}}$ : Compression force on L5-S1 for single activity i (N)

$\mathrm{t}_{\mathrm{i}}$ : Duration of daily exposure to single activity i (h)

Each act of lifting was calculated with a loading duration of 7.5s. To assess the calculated lumbar disc compression forces, standard threshold values, namely $3.5 \mathrm{kNh}$ for women and $5.5 \mathrm{kNh}$ for men were used. It is assumed that the risk for back disorders is increased once these reference values are exceeded [26].

\section{Data analysis}

To compare discrete variables - like orthopaedic findings and job related characteristics - between respondents in nursing homes and home-based care, chi-squared statistics were used, as well as analysis with the Mantel-Haenszel trend test where relevant. All continuous variables were assessed for normality using the Kolmogorov-Smirnov test. As no variable was normally distributed, the nonparametric Mann-Whitney test was used. All tests were applied two-tailed, and a significance level of 0.05 was chosen. Statistical analyses were performed using the SPSS version 14.0 for Windows.

\section{Results}

$81 \%$ of the nursing staff were working in nursing homes with exclusive or predominant inpatient care and $19 \%$ in home care services. Of the nursing homes, about $50 \%$ had more than 100 patient beds, 30\% between 70 and 100 beds and $20 \%$ fewer than 70 beds. The characteristics of the nursing staff for the two care settings are described in Table 1 . The staff in nursing homes were older than those in home care, had on the average worked for shorter periods in the nursing profession, had less often finished nursing training with an examination and were more frequently in full-time employment. The number of patients/residents to be cared for in each shift was higher in nursing homes than in home care, as was the proportion of patients needing intensive care, though homebased staff rarely had the possibility of requesting support from another nurse for patient transfers. Nursing staff in home care assessed their general state of health, their mental resources and their ability to handle the physical and psychological demands of the job as being better than staff in nursing homes. There was no difference between nursing staff in nursing homes and home-based care with 
Table I: Characteristics of nursing staff, by care setting

\begin{tabular}{|c|c|c|c|c|}
\hline & $\begin{array}{c}\text { Total } \\
\mathrm{n}=1390 \\
\%\end{array}$ & $\begin{array}{c}\text { Nursing homes } \\
\mathbf{n}=\mathrm{I}_{\mathrm{I}} \mathbf{2 6} \\
\%\end{array}$ & $\begin{array}{c}\text { Home care } \\
n=264 \\
\%\end{array}$ & $\begin{array}{c}\text { p- } \\
\text { value }\end{array}$ \\
\hline Female gender & 88 & 87 & 90 & $>0.05$ \\
\hline \multicolumn{5}{|l|}{ Age (years) } \\
\hline - under 30 & 18 & 18 & 15 & \\
\hline - 30 to 49 & 60 & 59 & 68 & \\
\hline - over 50 & 22 & 23 & 17 & $<0.05$ \\
\hline \multicolumn{5}{|l|}{ School educational level (years) } \\
\hline - Low $(\leq 9)$ & 37 & 40 & 26 & \\
\hline - Medium (10-II) & 45 & 43 & 52 & \\
\hline - High $(\geq 12)$ & 18 & 17 & 22 & $<0.001$ \\
\hline \multicolumn{5}{|l|}{ Nursing degree } \\
\hline - Registered nurse & 26 & 20 & 50 & \\
\hline - Registered geriatric nurse & 34 & 37 & 20 & \\
\hline - Nursing aides', assistant nurses & 21 & 24 & 10 & \\
\hline - Nursing auxiliaries & 19 & 19 & 20 & $<0.001$ \\
\hline Full-time employment ( $\geq 35$ h/week) & 49 & 53 & 31 & $<0.001$ \\
\hline \multicolumn{5}{|c|}{$\begin{array}{l}\text { Number of residents per shift } \\
\text { (including those requiring intensive care in \%) }\end{array}$} \\
\hline$-\leq 10(\leq 50 \%)$ & 30 & 26 & 52 & \\
\hline$-\leq 10(>50 \%)$ & 12 & 13 & 4 & \\
\hline$->10(\leq 50 \%)$ & 39 & 38 & 42 & \\
\hline$->10(>50 \%)$ & 19 & 23 & 2 & $<0.001$ \\
\hline Support possible from another nurse & 86 & 95 & 50 & $<0.001$ \\
\hline \multicolumn{5}{|c|}{$\begin{array}{l}\text { Participation during the preceding } 12 \text { months in measures to prevent back } \\
\text { disorders }\end{array}$} \\
\hline - No measure & 62 & 63 & 57 & \\
\hline - Primary preventive measure ${ }^{2}$ & 29 & 27 & 36 & \\
\hline \multirow[t]{2}{*}{ - Secondary preventive measure ${ }^{3}$} & 9 & 10 & 7 & $<0.05$ \\
\hline & Median (Quartile) & Median (Quartile) & Median (Quartile) & \\
\hline Years worked in the nursing profession & II $(6-20)$ & $11(6-19)$ & $16(8-24)$ & $<0.001$ \\
\hline
\end{tabular}

'Chi square test for differences between nursing staff in nursing homes and home care.

2Participation in workplace prevention program (use of low tech ergonomic aids, back school).

${ }^{3}$ Treatment in a rehabilitation program for back disorders, consultation with the facility physician.

respect to duration of sick leave due to back pain and BMI (Table 2).

On the day of the examination, $18 \%$ of the staff in nursing homes complained of symptoms in the lumbar spine and $11 \%$ in the cervical spine (Table 3 ). There was no difference between nursing staff in nursing homes and homebased care with respect to pain intensity in the lumbar spine. In the cervical spine, pain intensity was lower for staff in nursing homes. In both groups, about one fifth of all staff suffered intense to highly intense pain in the lumbar and cervical spines.

About $60 \%$ of nursing staff in both groups were given the more extensive tests in the complementary examination.
Of the 13 orthopaedic findings in the lumbar spine, 10 were significantly more often abnormal in staff active in nursing homes than in home care (Table 3). The findings were mostly functional restrictions (including the Schober Index, the Kemp sign, and inclination and lateral inclination in the area of the lumbar spine), as well as abnormalities in the SLR test and in the heel to buttocks distance. However, these are non-pathological findings, such as muscular pain and an intense feeling of stretching. Nerve pain in the SLR test or in the heel to buttocks distance is an expression of irritation in the nerve root. This occurred in less than $1 \%$ of the nursing staff in both groups. Examination of the cervical spine showed that the mobility in the neck and shoulder region was also more often restricted in staff in nursing homes. These findings pre- 
Table 2: Work ability (WA) and general state of health of nursing staff, by care setting

\begin{tabular}{|c|c|c|c|}
\hline & $\begin{array}{c}\text { Nursing homes } \\
\mathbf{n}=\mathrm{I}_{\mathrm{I}} \mathbf{2 6} \\
\%\end{array}$ & $\begin{array}{c}\text { Home care } \\
n=264 \\
\%\end{array}$ & p-value \\
\hline \multicolumn{4}{|c|}{ WA in relation to the physical and psychological demands of the job } \\
\hline - rather good to very good & 43 & 57 & \\
\hline - intermediate to very poor & 57 & 43 & $<0.01$ \\
\hline \multicolumn{4}{|l|}{ Mental resources' } \\
\hline - rather high & 78 & 90 & \\
\hline - rather slight & 22 & 10 & $<0.001$ \\
\hline \multicolumn{4}{|l|}{ General state of health } \\
\hline - good to excellent & 82 & 91 & \\
\hline - less good to poor & 18 & 9 & $<0.01$ \\
\hline \multicolumn{4}{|c|}{ Duration of sick leave due to back pain } \\
\hline - none sick leave & 83 & 87 & ns \\
\hline - sick leave up to 4 weeks & 13 & 10 & \\
\hline - sick leave more than 4 weeks & 4 & 3 & \\
\hline \multicolumn{4}{|l|}{ BMI } \\
\hline$-<25$ & 40 & 45 & ns \\
\hline$-25-<30$ & 36 & 34 & \\
\hline$-\geq 30$ & 24 & 21 & \\
\hline
\end{tabular}

I Composed of the items "pleasure in daily work", "active and alert" and "confident for the future; related to the last 3 months.

dominantly indicate functional restriction, but may nevertheless be linked to considerable impairments in quality of life and performance.

Measures for primary prevention like training in lifting techniques and use of assistive devices were more often used by home care staff. Staff in nursing homes had more often participated in rehabilitation programs (Table 1).

In $76 \%$ of the nursing homes, the ergonomic conditions of the workplace were comparatively good. These facilities were exclusively equipped with height adjustable patients beds, of which $82 \%$ were electric beds (data not shown). About $90 \%$ of the nursing staff reported that they either occasionally or almost always adjusted the height of the bed to their working procedures (Table 4). Home-based staff more rarely carried out nursing functions at the patient bed with back-protecting work practices than did their colleagues in nursing homes (Table 4). Technical lifting aids were in almost all nursing homes (more than $90 \%$ ), where they were regularly used (no table). Patient lifting poles were available in about half of all nursing homes (approx. 40\%). Low tech ergonomic aids were available in about a third of nursing homes. However, they were only actually used in about two thirds of the facilities in which they were present (data not shown).

Ten of the twelve load related activities occurred significantly more often for staff in nursing homes, including activities such as changing the patient's position in the bed, shifting the patient up to the bed, and raising the patient from the lying position to sitting (data not shown). Calculation of the lumbar load showed that $90 \%$ of the female and $38 \%$ of the male staff were above the gender-specific reference values for the daily dose (no table). For $45 \%$ of the staff in nursing homes, the resulting lumbar load was found to be above the reference value of $5.5 \mathrm{kNh}$ for men, in comparison to the figure of only $6.4 \%$ for staff in home care. The median lumbar load for staff in nursing homes was $5.4 \mathrm{kNh}$, in comparison to $3.5 \mathrm{kNh}$ for home care staff (Figure 1). There was no difference between male and female staff with respect to the median lumbar load.

\section{Discussion}

Many studies on the situation in long-term health care have concentrated on geriatric care. In the present study, we have examined the prevalence of orthopaedic findings in the back and of the lumbar load for care activities in a group of 1390 health care workers in 86 nursing homes and home care facilities. Our results show that staff in nursing homes more often gave positive orthopaedic findings and more often complained of symptoms in the cervical spine. At the same time, staff in home-based care had a more favourable impression of the condition of their general health, their work ability in relation to the demands of the work and their mental resources than did their colleagues in nursing homes. This agrees with the 
Table 3: Back disorders of nursing staff, by care setting

\begin{tabular}{|c|c|c|c|}
\hline & $\begin{array}{c}\text { Nursing homes } \\
\mathbf{n}=\mathrm{I}_{\mathrm{I}} \mathbf{2 6} \\
\%\end{array}$ & $\begin{array}{c}\text { Home care } \\
n=264 \\
\%\end{array}$ & p-value ${ }^{l}$ \\
\hline \multicolumn{4}{|l|}{ Back pain on the examination day ${ }^{2}$} \\
\hline - in the lumbar spine & 18 & 16 & n.s. \\
\hline - in the cervical spine & 11 & 4 & $<0.001$ \\
\hline \multicolumn{4}{|c|}{ Pain intensity in the lumbar spine in the last 4 weeks ${ }^{3}$} \\
\hline - none to mild & 55 & 56 & \\
\hline - moderate & 24 & 24 & \\
\hline - intense to very intense & 21 & 20 & ns \\
\hline \multicolumn{4}{|c|}{ Pain intensity in the cervical spine in the last 4 weeks $^{3}$} \\
\hline - none to mild & 57 & 63 & \\
\hline - moderate & 25 & 23 & \\
\hline - intense to very intense & 18 & 14 & $<0.05$ \\
\hline \multicolumn{4}{|l|}{ Disorders in the lumbar spine } \\
\hline Schober reclination $(\geq 10 \mathrm{~cm})$ & 10 & 3 & $<0.01$ \\
\hline Schober inclination $(<13 \mathrm{~cm})$ & 31 & 22 & $<0.01$ \\
\hline Inclination painful & 11 & 5 & $<0.01$ \\
\hline Reclination painful & 11 & 8 & ns \\
\hline Kemp sign positive & 17 & 9 & $<0.001$ \\
\hline Painful arc & 6 & 5 & ns \\
\hline Climbing up the legs & 5 & 2 & $<0.05$ \\
\hline Percussion painful & 11 & 7 & $<0.01$ \\
\hline Pain in heel-fall test & 5 & 5 & ns \\
\hline Lateral inclination painful ${ }^{4}$ & 18 & 11 & $<0.01$ \\
\hline Pain during the straight leg raise test ${ }^{4}$ & 32 & 13 & $<0.001$ \\
\hline Lasèque sign ${ }^{4}$ & 2 & 1 & ns \\
\hline Heel to buttocks distance $(>29 \mathrm{~cm})^{4}$ & 4 & 5 & ns \\
\hline Pain during the heel to buttocks distance 4 & 26 & 13 & $<0.001$ \\
\hline Pain on stretching the femur ${ }^{4}$ & 7 & 2 & $<0.01$ \\
\hline \multicolumn{4}{|l|}{ Disorders in the cervical spine } \\
\hline Lateral inclination/flexion or extension painful & 16 & 11 & $<0.01$ \\
\hline Ott index $(\leq 3 \mathrm{l} \mathrm{cm})$ & 27 & 24 & ns \\
\hline Percussion painful & 6 & 3 & $<0.05$ \\
\hline Pain in heel-fall test & $<1$ & I & ns \\
\hline
\end{tabular}

I ns = non-significant.

2 Taken from the medical history.

3 Taken from the questionnaire (self-reported data).

${ }^{4}$ Findings on the right and/or left leg.

study by Hasson and Arnetz, which found that home care staff experienced significantly less physical and emotional strain compared with staff in nursing homes [18]. There have been few studies dealing with geriatric nursing staff as a separate group of health care workers; one of these is the NEXT study. Our findings agree with those of the NEXT study, in that staff in nursing homes more often report complaints from disorders of the cervical or lumbar spine than do staff in home care [16]. The NEXT study also reported a trend towards less favourable values for the work ability of staff in nursing homes $[16,29]$. When comparing the prevalence data, it should be remembered that studies on the prevalence of occupational back diseases frequently have different objectives and target variables, so that direct comparison is difficult [30]. The present study contains a systematic collection of orthopaedic findings, which is recommended in occupational medicine for the timely recognition of suspicious findings for avoiding excessive or inappropriate lumbar load [19]. In our study, nearly every second staff in elderly care had positive orthopaedic findings. However, these were not manifest orthopaedic diseases, but functional restrictions to the locomotor system. In the present study, serious findings indicating disorders related to the intervertebral bodies (nerve pain in the SLR test and pain on stretching the femur) were only made in $2 \%$ of the study group - a somewhat lower proportion than in another study with active community nurses [3]. The idea that most cases in our 
Table 4: Back-protecting work practices at the patient bed performed by nursing staff, separated by care setting

\begin{tabular}{|c|c|c|c|}
\hline & $\begin{array}{c}\text { Nursing homes } \\
n=1 \text { I } 26 \\
\%\end{array}$ & $\begin{array}{c}\text { Home care } \\
n=264 \\
\%\end{array}$ & p-value \\
\hline \multicolumn{4}{|c|}{ Adjusting height of bed is occasionally/almost always performed: } \\
\hline - Changing the patient's position & 98 & 92 & $<0.001$ \\
\hline - Mobilisation & 93 & 94 & ns \\
\hline - Basic nursing & 96 & 98 & ns \\
\hline - Technical nursing & 93 & 94 & ns \\
\hline \multicolumn{4}{|l|}{ Push bed away from wall } \\
\hline - Occasionally/almost always & 91 & 78 & $<0.001$ \\
\hline - Rarely/never & 9 & 22 & \\
\hline \multicolumn{4}{|l|}{ Bed rail let down } \\
\hline - Occasionally/almost always & 98 & 95 & $<0.05$ \\
\hline - Rarely/never & 2 & 5 & \\
\hline
\end{tabular}

I ns = non-significant.

study were not suffering from serious diseases is supported by the fact that only every sixth staff member was on sick leave due to back problems in the year preceding the survey. Other studies investigating staff in nursing homes and general hospitals have reported comparable figures for inability to work because of back pain [31].

Height adjustable patient beds and assistive devices can both be of great help in reducing lumbar load for care activities with patient transfer in geriatric care [32-35]. Nursing homes are very well equipped with height adjustable patient beds and with technical lifting aids, though their equipment with low tech ergonomic aids must be regarded as unsatisfactory. This is in line with the NEXT study, according to which technical lifting aids were available in $78 \%$ of nursing homes in Germany and more than
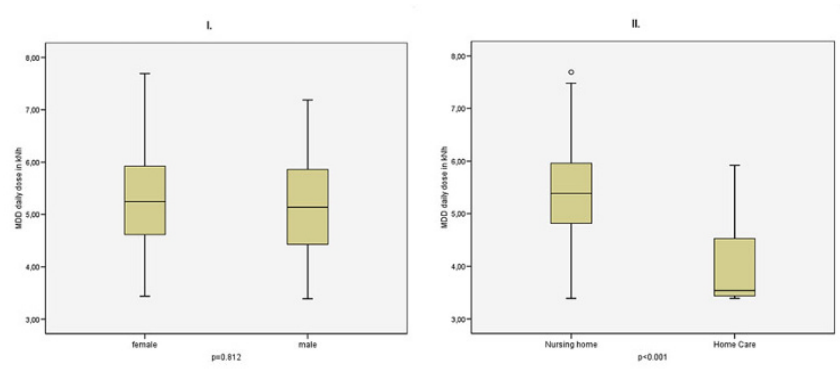

Figure I

Lumbar disc compression force of full-time nurses by gender (I) and care setting (II).
$90 \%$ of the staff used the available lifters [16]. Another study found somewhat lower figures of around $80 \%$ for use of technical lifters by geriatric nurses [36]. Data for the equipment with assistive devises of home-based staff were not assessed in our study; as no data have been published yet by other authors, further research is needed in this care setting. Homes-based staff is apparently more often forced to carry out patient transfers alone than happens in nursing homes. This agrees with the study by Owen and Staehler, which found that in home care a second assistant was only permitted by the agency because of the patient's weight and unwillingness to cooperate [37].

Altering the height of patient bed to ergonomic lift level is supposed to be a technique to reduce the frequency and extent of marked inclination of the trunk [38] and was adopted by staff in both care settings. Additional backprotecting work practices at the patient's bed - such as lowering bed rails before nursing actions - seem to be less well established in home-based staff. Because of lack of data about the equipment, we can only speculate about the reasons for the inadequate implementation. It is expected that space for free movement around the patient's bed is restricted under real conditions in private homes [28].

In our study, staff in nursing homes was exposed to a much higher lumbar load than staff in home care. Except for the study by Theilmeier et al. [28], which used the same exposure assessment, we found no other published study of geriatric nurses that had calculated lumbar load for the sum of daily patient transfer activities. We found higher figures of lumbar load in nursing home staff and at the same time back disorders were significantly more often found in nursing home staff than in home-based staff. Our results are consistent with previous reports indicating a dose-relation between lifting of weights or work- 
ing postures with extreme forward bending and the development of lumbar disorders [39-41].

The validity of the reference values in the MDD procedure has currently been discussed in the field of occupational medicine [42] and modification has been proposed [39]. The original model is nevertheless useful to assess the lumbar load in nursing staff working in different care settings, as shown in the present study.

Calculation of the lumbar load was based on self-reported data. Misclassification is therefore possible. Nevertheless, any masking of effects in the comparison between staff in nursing homes and home care should be negligible. Data on the implementation of back-protecting work practices are also self-reported data by the respondents. For this reason, bias from subjective estimation cannot be excluded.

\section{Conclusions}

Staff in nursing homes reports more occupational exposure on the lumbar spine than home-based staff. Furthermore, staff in nursing homes had more abnormal orthopaedic findings, a higher lumbar load and reduced values for work ability. The present data therefore support the demand for consistent and vigorous implementation of preventive measures for staff in home-based care and to a much greater extent - in nursing homes. It appears necessary to provide advanced training to support working procedures conducive to back health which should be specifically adapted to the differences between both care settings. Additional studies are needed for more verified information about the working conditions in home care setting.

\section{Competing interests}

The authors declare that they have no competing interests.

\section{Authors' contributions}

KK performed the statistical analyses, interpreted the data and drafted the manuscript. MD participated in the design of the study, interpreted the data and drafted the manuscript. AN participated in the design of the study and interpreted the data. BBB participated in the coordination of the study and helped to draft the manuscript. All authors read and approved the manuscript.

\section{Additional material}

\section{Additional file 1}

Diagnostic procedure of orthopaedic examination. Scheme for the orthopaedic examination performed in this study according to Grifka [19].

Click here for file

[http://www.biomedcentral.com/content/supplementary/17456673-4-33-S1.JPEG]

\section{References}

I. Neuhauser H, Ellert U, Ziese T: Chronic back pain in the general population in Germany 2002/2003: prevalence and highly affected population groups. Gesundheitswesen 2005, 67:685-693.

2. Byrns G, Reeder G, Jin G, Pachis K: Risk factors for work-related low back pain in registered nurses, and potential obstacles in using mechanical lifting devices. J Occup Environ Hyg 2004, I:II-2I.

3. Knibbe J], Friele RD: Prevalence of back pain and characteristics of the physical workload of community nurses. Ergonomics 1996, 39:186-198.

4. Bos E, Krol B, van der SL, Groothoff J: Risk factors and musculoskeletal complaints in non-specialized nurses, IC nurses, operation room nurses, and X-ray technologists. Int Arch Occup Environ Health 2007, 80: 198-206.

5. Dulon M, Kromark K, Skudlik C, Nienhaus A: Prevalence of skin and back diseases in geriatric care nurses. Int Arch Occup Environ Health 2008, 81 : 983-92.

6. Martimo KP, Verbeek J, Karppinen J, Furlan AD, Kuijer PP, Viikari-Juntura $E$, et al: Manual material handling advice and assistive devices for preventing and treating back pain in workers. Cochrane Database Syst Rev 2007:CD005958.

7. Schulz E, Leidl R, König HH: Starker Anstieg der Pflegebedürftigkeit zu erwarten - Vorausschätzungen bis $\mathbf{2 0 2 0}$ mit Ausblick auf 2050. Wochenbericht 200I, 68:65-77.

8. Blinkert B, Klie T: Zukünftige Entwicklung des Verhältnisses von professioneller und häuslicher Pflege bei differierenden Arrangements und privaten Ressourcen bis zum Jahr 2050. Expertise im Auftrag der EnqéteKommission Demographischer Wandel des Deutschen Bundestages Berlin/ Freiburg; $200 \mathrm{I}$.

9. Glaser J, Richter G, Lampert B, Weigl M: Belastungsscreening bei Altenpflegekräften. In Psychologie der Arbeitssicherheit und Gesundheit. Arbeitsschutz, Gesundheit und Wirtschaftlichkeit: 2I-23 May 2007; Potsdam Edited by: Bärenz P, Metz AM, Rothe HJ. Kröning:Asanger Verlag; 2007:369-372.

10. Zimber A, Albrecht A, Weyerer S: Die Beanspruchung in der stationären Altenpflege. Pflege Aktuell 2000, 54:272-275.

II. Freitag S, Ellegast R, Dulon M, Nienhaus A: Quantitative measurement of stressful trunk postures in nursing professions. Ann Occup Hyg 2007, 5 1:385-395.

12. Kromark K, Dulon M, Nienhaus A: Health indicators and preventive behaviour of older employees in geriatric care. Gesundheitswesen 2008, 70:137-|44.

13. Nienhaus A: Unfälle bei Berufskrankheiten im Jahr 2002. In Gefährdungsprofile - Unfälle und arbeitsbedingte Erkrankungen in Gesundheitsdienst und Wohlfahrtspflege Edited by: Nienhaus A. Landsberg/ Lech: ecomed Medizin; 2005: 14-34.

14. Federal Statistical Office: Pflegestatistik 2007 - Pflege im Rahmen der Pflegeversicherung - 3. Bericht: Ländervergleich ambulante Pflegedienste. Statistisches Bundesamt. 9-32009. Wiesbaden.

15. Federal Statistical Office: Pflegestatistik 2007 - Pflege im Rahmen der Pflegeversicherung - 4. Bericht: Ländervergleich Pflegeheime. Statistisches Bundesamt. 9-3-2009. Wiesbaden.

16. Simon M, Tackenberg P, Nienhaus A, Estryn-Behar M, Conway MP, Hasselhorn HM: Back or neck-pain-related disability of nursing staff in hospitals, nursing homes and home care in seven countries-results from the European NEXT-Study. Int J Nurs Stud 2007, 45:24-34.

17. Gerdle B, Brulin C, Elert J, Granlund B: Factors interacting with perceived work-related complaints in the musculoskeletal system among home care service personnel. An explorative multivariate study. Scand J Rehabil Med 1994, 26:5I-58.

18. Hasson H, Arnetz JE: Nursing staff competence, work strain, stress and satisfaction in elderly care: a comparison of homebased care and nursing homes. J Clin Nurs 2008, 17:468-48I.

19. Grifka J, Tingart M, Hofbauer R, Peters T: Development and trial use of multistep diagnosis of musculoskeletal disorders during a routine physical examination at the workplace. Orthopäde 2002, 3 1:973-980.

20. Tingart M, Lerch K, Hofbauer R, Grifka J: Principles of the multistep diagnosis: An instrument for the diagnosis o musculoskeletal disorders. Arbeitsmed Sozialmed Umweltmed 2003, 38:6-10. 
21. Hartmann B, Spallek M, Liebers F, Schwarze S, Linhardt O: Guideline for diagnosis of musculosceletal disease of occupational health screening - Attachment at G46 "Exposure of the musculosceletal system". Arbeitsmed Sozialmed Umweltmed 2006, 4I:5-I5.

22. Hasselhorn HM, Freude G: Der Work Ability Index - ein Leitfaden Dortmund/Berlin/Dresden: Wirtschaftsverlag NW; 2007.

23. Tuomi K, Ilmarinen J, Jahkola A, Katajarinne L, Tulkki A: Work Ability Index 2nd edition. Helsinki: Finnish Institute of Occupational Health; 1998.

24. Von Korff M, Ormel J, Keefe FJ, Dworkin SF: Grading the severity of chronic pain. Pain 1992, 50:133-149.

25. Taylor H, Curran NM: The Nuprin pain report New York: Louis Harris; 1985.

26. Jäger M, Luttmann A, Bolm-Audorff U, Schäfer K, Hartung E, Kuhn S, et al:: Mainz-Dortmunder Dosismodell (MDD) zur Beurteilung der Belastung der LWS durch Heben oder Tragen schwerer Lasten oder durch Tätigkeiten in extremer Rumpfbeugehaltung bei Verdacht auf Berufskrankheit Nr. 2108 - Teil I: Retrospektive Belastungsermittlung für risikobehaftete Tätigkeitsfelder. Arbeitsmed Sozialmed Umweltmed 1999, 34: 10I-III.

27. Hartung E, Schäfer K, Jäger M, Luttmann A, Bolm-Audorff U, Kuhn S, et al.: Mainz-Dortmunder Dosismodell (MDD) zur Beurteilung der Belastung der LWS durch Heben oder Tragen schwerer Lasten oder durch Tätigkeiten in extremer Rumpfbeugehaltung bei Verdacht auf Berufskrankheit Nr. 2108 - Teil 2: Vorschlag zur Beurteilung der arbeitstechnischen Voraussetzungen im Berufskrankheiten-Festestellungsverfahren. Arbeitsmed Sozialmed Umweltmed 1999, 34: II $12-122$.

28. Theilmeier A, Jordan C, Wortmann N, Kuhn S, Nienhaus A, Luttmann $A$, et al: Stress on the lumbar spine of nurses during patient transfer-Parameters for use in procedure for establishing occupational disease. Zbl Arbeitsmed 2006, 56:228-25I.

29. Simon M, Tackenberg $P$, Hasselhorn HM, Kümmerling $A$, Büscher $A$, Müller BH: Auswertung der ersten Befragung der Next-Studie in Deutschland. Universität Wuppertal; 2005.

30. Seidler A, Liebers F, Latza U: Prevention of low back pain at work. Bundesgesundheitsblatt Gesundheitsforschung Gesundheitsschutz 2008, 5 I:322-333.

31. Alexopoulos EC, Burdorf A, Kalokerinou A: A comparative analysis on musculoskeletal disorders between Greek and Dutch nursing personnel. Int Arch Occup Environ Health 2006, 79:82-88.

32. Bos EH, Krol B, Van Der SA, Groothoff JW: The effects of occupational interventions on reduction of musculoskeletal symptoms in the nursing profession. Ergonomics 2006, 49:706-723.

33. Walls C: Do electric patient beds reduce the risk of lower back disorders in nurses? Occup Med (Lond) 200I, $51: 380-384$.

34. Takala EP, Kukkonen R: The handling of patients on geriatric wards. A challenge for on-the-job training. Appl Ergon 1987, I8:17-22.

35. de Looze MP, Zinzen E, Caboor D, Heyblom P, van BE, Van RP, et al: Effect of individually chosen bed-height adjustments on the low-back stress of nurses. Scand J Work Environ Health 1994, 20:427-434.

36. Kromark K, Metzing S, Bartholomeyczik S, Liersch A, Nienhaus A: Equipment and use of equipment in nursing homes. Gesundheitswesen 2006, 68:41-47.

37. Owen BD, Staehler KS: Decreasing back stress in home care. Home Healthc Nurse 2003, 21:180-186.

38. Freitag S, Fincke I, Dulon M, Ellegast R, Nienhaus A: Messtechnische Analyse von ungünstigen Körperhaltungen bei Pflegekräften - eine geriatrische Station im Vergleich mit anderen Krankenhausstationen. Ergo Med 2007, 3 I: I30-I40.

39. Seidler A, Bolm-Audorff U, Heiskel H, Henkel N, Roth-Kuver B, Kaiser $U$, et al.: Relationship between cumulative spinal load due to materials handling and lumbar disc herniation - Results of the German Spine Study. Occup Environ Med 200I, 58:735-746.

40. Seidler A, Bergmann A, Ditchen D, Ellegast R, Elsner G, Grifka J, et al.: Relationship between manual materials handling and lumbar chondrosis - Results of the German Spine Study. Zbl Arbeitsmed 2007, 57:290-303.

41. Bolm-Audorff U, Bergmann A, Ditchen D, Ellegast R, Elsner G, Grifka J, et al.: Relationship between manual materials handling ans lumbar chondrosis - Results of the German Spine Study. Z $\mathrm{Zl}$ Arbeitsmed 2007, 57:304-316.

42. Hartmann B: Zur Diskussion Was sagt uns die Deutsche Wirbelsäulenstudie? Zbl Arbeitsmed 2007, 57:365-368.
Publish with Bio Med Central and every scientist can read your work free of charge

"BioMed Central will be the most significant development for disseminating the results of biomedical research in our lifetime. "

Sir Paul Nurse, Cancer Research UK

Your research papers will be:

- available free of charge to the entire biomedical community

- peer reviewed and published immediately upon acceptance

- cited in PubMed and archived on PubMed Central

- yours - you keep the copyright

Submit your manuscript here:

http://www.biomedcentral.com/info/publishing_adv.asp
BioMedcentral 